\title{
Cell lineage allocation in equine blastocysts produced in vitro under varying glucose concentrations
}

\author{
Young-Ho Choi, Pablo Ross ${ }^{1}$, Isabel C Velez, B Macías-García, Fernando L Riera ${ }^{2}$ \\ and Katrin Hinrichs \\ Department of Veterinary Physiology and Pharmacology, College of Veterinary Medicine \& Biomedical Sciences, \\ Texas A\&M University, College Station, Texas 77843-4466, USA, ${ }^{1}$ Department of Animal Science, University of \\ California, Davis, Davis, California 95616, USA and ${ }^{2}$ Laboratorio de Reproducción Equina Prof. Robert M. Kenney, \\ Doña Pilar Embriones SRL, Lincoln, Argentina
}

Correspondence should be addressed to K Hinrichs; Email: khinrichs@cvm.tamu.edu

\begin{abstract}
Equine embryos develop in vitro in the presence of high glucose concentrations, but little is known about their requirements for development. We evaluated the effect of glucose concentrations in medium on blastocyst development after ICSI. In experiment 1 , there were no significant differences in rates of blastocyst formation among embryos cultured in our standard medium (DMEM/F-12), which contained $>16 \mathrm{mM}$ glucose, and those cultured in a minimal-glucose embryo culture medium ( $<1 \mathrm{mM}$; Global medium, GB), with either 0 added glucose for the first 5 days, then $20 \mathrm{mM}(0-20)$ or $20 \mathrm{mM}$ for the entire culture period (20-20). In experiment 2, there were no significant differences in the rates of blastocyst development (31-46\%) for embryos cultured in four glucose treatments in GB (0-10, 0-20, 5-10, or 5-20). Blastocysts were evaluated by immunofluorescence for lineage-specific markers. All cells stained positively for POU5F1. An inner cluster of cells was identified that included presumptive primitive endoderm cells (GATA6-positive) and presumptive epiblast (EPI) cells. The 5-20 treatment resulted in a significantly lower number of presumptive EPI-lineage cells than the 0-20 treatment did. GATA6-positive cells appeared to be allocated to the primitive endoderm independent of the formation of an inner cell mass, as was previously hypothesized for equine embryos. These data demonstrate that equine blastocyst development is not dependent on high glucose concentrations during early culture; rather, environmental glucose may affect cell allocation. They also present the first analysis of cell lineage allocation in in vitro-fertilized equine blastocysts. These findings expand our understanding of the factors that affect embryo development in the horse.

Reproduction (2015) 150 31-41
\end{abstract}

\section{Introduction}

ICSI has become the method of choice for the fertilization of equine oocytes in the laboratory because of the failure of standard IVF in this species (see Hinrichs (2010)). However, success in equine in vitro embryo production is variable, and few laboratories have reported repeatable blastocyst rates of more than $15 \%$ per injected oocyte. In relation to this, there is remarkably little information available on the factors that affect blastocyst formation in equine in vitro culture systems.

Early work on equine in vitro culture used media developed for embryo culture in other species but reported poor blastocyst development (Dell'Aquila et al. 1997, Li et al. 2001, Choi et al. 2003a). Choi et al. (2004a) then performed a direct comparison of media for the culture of equine ICSI-produced embryos and found that blastocyst development per injected oocyte in the multi-species embryo culture medium
G1.3/G2.3 (Gardner et al. 1998, Lane et al. 2003) was $2 \%$, whereas blastocyst development in DMEM/F-12, a complete cell-culture medium, was 18\%. Subsequently, the use of DMEM/F-12 with $10 \%$ FBS in a low-oxygen environment has been used with resulting blastocyst rates that were generally between $25-35 \%$, and as high as 43\% (Hinrichs et al. 2005, Choi et al. 2006, 2007, Ribeiro et al. 2008, Jacobson et al. 2010), and DMEM/ $\mathrm{F}-12$ has become one of the standard media used for equine embryo culture.

DMEM/F-12 is a complex medium formulated for tissue culture, and it contains many components that are reported to be detrimental to embryo development in other species, such as high phosphate concentrations, divalent metal ions, and nucleotides (Lane \& Gardner 2007). In particular, DMEM/F-12 contains a high glucose concentration $(17.5 \mathrm{mM}$; $\sim 16.5 \mathrm{mM}$ when prepared with $10 \%$ serum). The ability of DMEM/F-12 to support equine blastocyst development has been attributed to 
this high glucose concentration, because metabolic studies have shown high glucose uptake and metabolism in in vivo-recovered equine blastocysts (Rieger et al. 1987, Lane et al. 2001). However, there is little direct information available on the effects of glucose during in vitro embryo development in the horse. The presence of either 0.55 or $5.5 \mathrm{mM}$ glucose supported high cleavage rates and nucleus number at day 4 in equine embryos cultured in a modified Chatot, Ziomek, Bavister (CZB) medium (CZB-C; Choi et al. 2004b); nevertheless, no blastocysts were obtained after 7.5 days of culture in this medium (Choi et al. 2004a). Similarly, equine blastocyst development was low (2-9\%; Choi et al. 2003a, 2004a) in the commercial two-step embryo culture medium G1/G2 (Lane et al. 2003), which contained 0.5/3.15 mM glucose. To the best of our knowledge, the direct comparison of higher glucose concentrations (approximating those present in DMEM/F-12) have been examined in only one brief report (Herrera et al. 2008). These authors evaluated equine embryo development in a modified synthetic oviductal fluid with $0,1.5$, or $19 \mathrm{mM}$ added glucose; advanced development (morula + blastocyst) rates were $4.3,8.7$, and $28 \%$ respectively per injected oocyte. Collectively, these findings suggest that equine embryos require glucose levels of more than 3-5 mM for at least some stage of their growth in order to develop optimally in vitro.

In most other species, excessive medium glucose is detrimental to embryo development (Schini \& Bavister 1988, Seshagiri \& Bavister 1991, Takahashi \& First 1992, Thompson et al. 1992, Conaghan et al. 1993). The early cleavage-stage embryo may be especially sensitive to the effects of glucose, because the metabolism of embryos of many species changes from a reliance on oxidative phosphorylation of lactate or pyruvate (which may be inhibited by excess glycolytic activity) during the early cleavage stages to glycolysis at the compactedmorula stage and into blastocyst development as metabolic requirements increase to support growth and differentiation (Rieger et al. 1992, Gardner 1998). This change in nutrient usage has also been reported in equine embryos (recovered from the uterus in vivo): morulae utilized mainly lactate and pyruvate, whereas expanded blastocysts utilized mainly glucose (Lane et al. 2001). The presence of excess medium glucose (e.g., $5 \mathrm{mM}$ ) during cleavage-stage culture has been shown to inhibit respiration in hamster embryos (Seshagiri \& Bavister 1991) and to decrease the rate of the subsequent development of blastocysts in the mouse, bovine, and hamster (Chatot et al. 1989, Furnus et al. 1997, Ludwig et al. 2001). For these reasons, many in vitro embryo culture systems incorporate two stages, a more simple, low-glucose medium (e.g., $<1 \mathrm{mM}$ ) to support the early cleavage-stage embryo and a more complex, higher-glucose medium (e.g., $\sim 5 \mathrm{mM}$ ) to support blastocyst development. The success of DMEM/ F-12-based media at $>16 \mathrm{mM}$ glucose as a one-step medium for supporting equine blastocyst development is therefore notable.

In other species, the effects of excess glucose may be greater in specific cell lineages; for example, in mice, excess glucose ( $28 \mathrm{mM}$ for $24 \mathrm{~h}$ ) was associated with increased reactive oxygen species and apoptosis of inner cell mass (ICM) cells (Leunda-Casi et al. 2002). Similarly, in rat embryos, culture in the presence of $17 \mathrm{mM}$ glucose reduced both the actual ICM cell number (by $34 \%$ ) and the ratio of ICM cells to trophoblast cells (De Hertogh et al. 1991). It has been difficult to establish methods to objectively evaluate the contribution of specific cell lineages in equine in vitro-produced blastocysts. Differential staining to enable the evaluation of ICM cells vs trophoblast cells in in vitro-produced blastocysts was ineffective because of the presence of an inner loose network of cells that filled the entire trophoblastic cavity and the absence of a defined ICM (Hinrichs et al. 2007). Immunostaining for POU5F1 also was not effective in revealing ICM cells in these embryos, because the entire in vitro-produced blastocyst was POU5F1-positive (Choi et al. 2009).

In the present study, we evaluated the effect of glucose concentrations on equine embryo development using a commercially available human embryo culture medium (Global medium, GB), which, as supplied, has negligible glucose (D. Rieger, personal communication, 2010; 0.2 $\mathrm{mM}$ on analysis by an independent laboratory, Morbeck et al. 2014). We supplemented this medium with glucose either throughout the embryo culture or only for the period after the time corresponding to the morula-toblastocyst transition in vivo (after day 5; entry of the embryo from the oviduct to the uterus in the horse; Freeman et al. 1991). To assess embryo quality, we evaluated POU5F1 staining combined with markers for trophoblast and endoderm (CDX2 and GATA6) to differentiate the three blastocyst cell lineages.

The overall goal of these studies was to better delineate the factors that affect the development of equine embryos in vitro.

\section{Materials and methods}

\section{General methods}

\section{Collection and maturation of oocytes}

Immature oocytes were collected either from slaughterhouse tissue (experiment 1, conducted in Argentina) or from the ovaries of live mares (experiments 2 and 3, conducted in Texas). Ovaries obtained at the slaughterhouse were transported in a Styrofoam box for $2 \mathrm{~h}$; the temperature upon arrival was $23-28^{\circ} \mathrm{C}$. Oocytes were obtained by scraping the follicles, and they were classified as having a compact cumulus (Cp), as having an expanded cumulus (Ex), or as degenerating, as described previously (Hinrichs et al. 1993, 2005).

Oocytes from live mares were recovered from a herd of 12 Quarter Horse mares by transvaginal ultrasound-guided 
follicle aspiration (TVA), as previously described (Jacobson et al. 2010). All experimental procedures were performed according to the United States Government Principles for the Utilization and Care of Vertebrate Animals Used in Testing, Research and Training and were approved by the Institutional Animal Care and Use Committee at Texas A\&M University. Briefly, all follicles $>5 \mathrm{~mm}$ in diameter were aspirated by TVA, with an interval of 14 days between aspirations in a given mare. There was no attempt to manipulate or stage the cycle between aspiration sessions. A 12-gauge double-lumen needle was used, and when possible, each follicle was flushed six times using M199 with Hanks' salts (Invitrogen) with 25 mM HEPES containing $0.4 \%$ FBS (Invitrogen), $8 \mathrm{IU} / \mathrm{ml}$ heparin (SigmaAldrich), and $25 \mu \mathrm{g} / \mathrm{ml}$ gentamicin (Invitrogen), during which time the follicle was curetted by rotation of the needle. The aspirated fluid was filtered through an embryo filter (EmCon filter, Immuno Systems, Inc., Spring Valley, WI, USA), and the oocytes were recovered from the collected cellular material.

Oocytes recovered by either method were washed twice and held in an EH holding medium (40\% M199 with Earle's salts (Invitrogen), 40\% M199 with Hanks' salts and 25 mM HEPES, and $20 \%$ FBS; Choi et al. 2006) at room temperature $\left(22-26^{\circ} \mathrm{C}\right)$ overnight (15-16 h) in a 1-ml vial, with minimal air space. The medium was prepared immediately before use; M199 with Earle's salts was not equilibrated before making the medium, nor was the medium equilibrated afterward. After holding, the oocytes were placed in M199 with Earle's salts that was supplemented with 10\% FBS, 5 mU FSH (Sioux Biochemicals, Sioux Center, IA, USA) and $25 \mu \mathrm{g} / \mathrm{ml}$ gentamicin, which had been equilibrated at $5 \% \mathrm{CO}_{2}$ and $38.2{ }^{\circ} \mathrm{C}$. The oocytes were cultured for $30 \mathrm{~h}$ in droplets of medium at a ratio of $10 \mu \mathrm{l}$ of medium per oocyte under light white mineral oil (SigmaAldrich or Sage, In-Vitro Fertilization, Inc., Trumbull, CT, USA) at $38.2{ }^{\circ} \mathrm{C}$ in a humidified atmosphere of $5 \% \mathrm{CO}_{2}$ in air.

\section{ICSI}

ICSI was conducted as described in our previous reports (Choi et al. 2002, 2011) with minor modifications, using modified CZB media, as detailed previously (Choi et al. 2003b). After maturation, the oocytes were denuded of cumulus by pipetting in $0.05 \%$ hyaluronidase (Sigma-Aldrich) in CZB-M, and those with a polar body were held in M199 with Earle's salts and $10 \%$ FBS in an atmosphere of $5 \% \mathrm{CO}_{2}$ in air at $38.2{ }^{\circ} \mathrm{C}$ before being used for ICSI with frozen-thawed sperm. Sperm were prepared for ICSI via a swim-up procedure. Semen was thawed at $38.2^{\circ} \mathrm{C}$ for $30 \mathrm{~s}$, and $200 \mu \mathrm{l}$ were layered under $1 \mathrm{ml} \mathrm{Sp-CZB}$. After $20 \mathrm{~min}$ incubation in air at $38.2{ }^{\circ} \mathrm{C}$, the top $0.6 \mathrm{ml}$ of the medium was collected, and the contained sperm were washed by centrifugation at $327 \mathrm{~g}$ for $3 \mathrm{~min}$, resuspension of the pellet in $1 \mathrm{ml} \mathrm{Sp-CZB}$, and re-centrifugation. The supernatant was removed, and the sperm pellet was resuspended in the remaining medium. For use in ICSI, $1 \mu \mathrm{l}$ of this sperm suspension was placed on the surface of a 3- $\mu$ l droplet of Sp-CZB that contained 10\% polyvinylpyrrolidone (PVP-360, Sigma-Aldrich), and motile sperm were identified after swimming down into the droplet. Sperm injection was carried out using the Piezo drill, with the stage warmer set at $32{ }^{\circ} \mathrm{C}$. The oocyte was held in a separate 50- $\mu$ l drop of CZB-M that contained 10\% FBS. A motile sperm in the sperm droplet was aspirated tail-first into the injection pipette (7-8 $\mu \mathrm{m}$ outer diameter). As the midpiece entered the pipette, the sperm was immobilized by pulses of the Piezo as the pipette was moved so that the edge of the pipette contacted the midpiece. The sperm was then drawn entirely into the injection pipette, and the pipette was moved to the oocyte droplet. The oocyte was held with the polar body at a position of either 6:00 or 12:00, whichever presented the clearest cytoplasm in the aspect of the oocyte closest to the holding pipette. A core of zona pellucida was removed using the injection pipette under pulses from the Piezo drill. The sperm was advanced within the injection pipette until it was near the tip. The pipette was introduced through the hole in the zona, and it was advanced into the oocyte until it was close to the opposite side of the oocyte (i.e., advanced through $\sim 80 \%$ of the oocyte diameter). A Piezo pulse was applied to break the oolemma, and, without aspiration of cytoplasm into the pipette, the sperm was ejected into the cytoplasm. Injected oocytes were held in CZB-H in $5 \% \mathrm{CO}_{2}$ in air at $38.2{ }^{\circ} \mathrm{C}$ for $1.5-2 \mathrm{~h}$ and were then placed in an embryo culture medium.

\section{Embryo culture}

After ICSI, presumptive zygotes were cultured either in DMEM/F-12 with $25 \mu \mathrm{g} / \mathrm{ml}$ gentamycin added or in a commercial human embryo culture medium (GB; LifeGlobal Group LLC, Guilford, CT, USA) with various levels of added glucose. The embryos were cultured in groups at a ratio of $1 \mu \mathrm{l}$ medium per embryo, with a minimum of two embryos and a maximum of five embryos per droplet; thus, the maximum droplet volume was $5 \mu \mathrm{l}$. All media were supplemented with $10 \%$ FBS. The glucose concentration in the FBS itself, as stated by the manufacturer, was $5.5 \mathrm{mM}$; thus, the addition of FBS resulted in a glucose concentration of $\sim 16.3 \mathrm{mM}$ in the DMEM/F-12-based medium and $\sim 0.73 \mathrm{mM}$ in the 0 -added glucose GB-based medium. In the glucose-added treatments, glucose (D-(+)-glucose, G-6152, Sigma-Aldrich) was added to GB medium that already contained $10 \%$ FBS by measuring the appropriate amount of glucose powder and dissolving it in the prepared medium. Embryos were cultured in $5 \% \mathrm{CO}_{2}$ (experiment 1) or $6 \% \mathrm{CO}_{2}$ (experiment 2), with $5 \% \mathrm{O}_{2}$ and the remainder $\mathrm{N}_{2}$ at $38.2{ }^{\circ} \mathrm{C}$. The medium was changed or refreshed at day 5 , and uncleaved oocytes were removed at this time. On evaluation at day 5, fragmentation could have been confused with cleavage; thus, the embryos kept in the culture were classified as 'presumptively cleaved'. Blastocyst development was evaluated on days 7 through 11. Embryos that showed organization of an outer presumptive trophoblast layer with a decreasing density of inner cells were considered to be blastocysts. Presumptive morulae were fixed in buffered formol saline, mounted on a slide with $6.5 \mu \mathrm{l}$ of 9:1 glycerol:PBS containing $2.5 \mu \mathrm{g} / \mathrm{ml}$ Hoechst 33258, and they were examined by fluorescence microscopy to determine the nucleus number. These embryos were classified as morulae if they contained more than 32 cells but did not have an organized outer rim of cells, and as blastocysts if they contained more than 64 cells and had begun the organization of outer presumptive trophoblast cells. 


\section{Immunocytochemistry}

Blastocysts resulting from experiment 2 were vitrified as they were produced. Vitrification was performed in open devices by an ethylene glycol vitrification/sucrose warming technique, as previously described (Choi et al. 2013).

After the completion of the study, vitrified blastocysts were warmed and cultured for $6 \mathrm{~h}$ in DMEM/F-12 with $20 \%$ FBS. To allow blastocyst expansion in vitro, the zona pellucida was then removed by placing the embryo into $100 \mu \mathrm{l}$ of $0.5 \%$ pronase in PBS at $38.2{ }^{\circ} \mathrm{C}$ and monitoring the embryo under the dissection microscope. When the zona pellucida started to dissolve, the embryo was removed from the pronase solution and washed three times in DMEM/F-12 with $20 \%$ FBS, during which time the zona was shed. The embryo was then placed back into $0.5 \mathrm{ml}$ of DMEM/F-12 with $20 \%$ FBS in one well of a four-well multi-dish (Nunc, Roskilde, Denmark) under oil in the culture environment described earlier for an additional $18 \mathrm{~h}$ (total culture time: $24 \mathrm{~h}$ ). This culture period was provided to determine if embryos were viable (showed growth over the culture period) and to allow embryos to undergo any initial development that might take place in the first $24 \mathrm{~h}$ after being transferred to the uterus of a recipient mare.

After culture, embryos were fixed in $4 \%$ paraformaldehyde and shipped to the laboratory of one of the co-authors (PR) at the University of California, Davis. There, embryos were permeabilized with D-PBS $+1 \%$ Triton X-100 for $30 \mathrm{~min}$ and blocked for $2 \mathrm{~h}$ in D-PBS $+0.1 \%$ Triton $\mathrm{X}-100+1 \% \mathrm{BSA}+10 \%$ normal donkey serum. Blastocysts were then incubated with primary antibodies overnight at $4{ }^{\circ} \mathrm{C}$. The antibodies used were mouse monoclonal against CDX2 (AM392; BioGenex, San Ramon, CA, USA), rabbit polyclonal against GATA6 (SC-9055; Santa Cruz Biotechnologies, Inc.), and goat polyclonal against POU5F1 (SC-8628; Santa Cruz Biotechnologies). After washing for three 10-min periods, and then three 20-min periods, the embryos were incubated with secondary antibodies at room temperature for $2 \mathrm{~h}$ (Alexa Fluor 488 donkey anti-goat IgG, Alexa Fluor 568 donkey anti-mouse IgG, and Alexa Fluor 647 donkey anti-rabbit IgG, all at 1:500 dilutions). Then, embryos were washed as described earlier, and the DNA was stained with Hoechst $33342(10 \mu \mathrm{g} / \mathrm{ml}$ for $10 \mathrm{~min})$. Finally, each individual embryo was mounted on a glass slide with Prolong Gold antifade reagent (Invitrogen). Z-stack images were captured at a fixed step of $1 \mu \mathrm{m}$ by a laser-scanning confocal microscope (Olympus FV1000) with a $40 \times$ apochromatic oil immersion objective (numerical aperture 1.0) and laser excitation and emission filters specific for Hoechst 33342, Alexa488, Alexa568, and Alexa647.

Cells were evaluated for total cell (nucleus) number and for number of trophoblast (TE, CDX2-positive), primitive endoderm (PE, GATA6-positive) and presumptive epiblast (EPI, CDX2-, and GATA6-negative) cells. To do this, maximum projection reconstructions of Z-stacks were generated by ImageJ-Fiji image processing software (National Institute of Health, Bethesda, MD, USA; Abràmoff et al. 2004). Because all of the cells stained positively for POU5F1 (see the 'Results' section), for EPI cell count, the fluorescence intensity of $C D X 2$ and GATA 6 was subtracted from that on the DNA image at each plane and then a maximum projection was generated for this image. Nikon Elements Software was then used to generate merged color images, and nuclei were counted by placing a marker on each counted cell. To avoid double counting, all cell types were counted on the same image by toggling between colors. Mitotic cells were recognized based on nuclear morphology in the DNA minus CDX2 and GATA6 images. The specificity of the immunostaining was confirmed on the staining of a day 8 in vivo-recovered equine blastocyst; the CDX2 antibody stained only the trophoblast, the GATA6 antibody stained only the primitive endoderm, and neither antibody stained the ICM (Supplementary Figure 1, see section on supplementary data given at the end of this article).

After cell counting, the morphological organization of the central cells was rated for each embryo by four independent observers that were blinded to glucose treatment as: 0 , minimal, or no EPI (DNA-stained only) cells present; 1, some EPI cells present, but few and not organized; 2, multiple EPI cells present, but not organized to one pole; or 3, multiple EPI cells present and organized toward one pole in an apparent ICM. The ratings for each embryo were averaged for an embryo ICM score.

Embryo warming and analysis were conducted until a minimum of five embryos had been analyzed in each culture treatment group.

\section{Experiment 1: comparison of DMEM/F-12 with $G B$ media}

Oocytes collected from slaughterhouse tissue were used for this study. Sperm from one stallion (Stallion XE) was used for ICSI. Three embryo culture media were compared: DMEM/F-12, with the medium refreshed on day 5; 0-20, GB medium containing no added glucose for the first 5 days of culture, then $20 \mathrm{mM}$ glucose from day 5 until the end of the culture; or 20-20, GB medium with $20 \mathrm{mM}$ added glucose throughout the culture, with the medium refreshed on day 5 . Three replicates were evaluated, and blastocyst development was compared among groups.

\section{Experiment 2: effect of glucose concentration during embryo culture}

Oocytes collected from live mares via TVA were used for this study. Sperm from one stallion (Stallion SP) was used for ICSI. A $2 \times 2$ design of added glucose concentrations during embryo culture was examined (0-10, 0-20, 5-10, and 5-20 mM; medium change on day 5). Two treatments were selected in random pairs to be performed in each replicate. The blastocysts produced were subjected to vitrification, warming, culture, and immunocytochemistry, as described earlier in the present paper. The rate of initial blastocyst development, the embryo diameter after culture, the morphological embryo ICM score, the total cell number, and the number and proportion of cells identified as presumptive trophoblast, primitive endoderm, and EPI, as determined by immunostaining, were compared among treatment groups.

\section{Experiment 3: effect of iso-osmolar medium throughout culture}

Because the addition of glucose resulted in increased osmolarity in the glucose-added treatments, we conducted a 
study to determine if this affected blastocyst development. To determine this, we examined the most extreme treatment (0-20). To achieve an iso-osmolar $20 \mathrm{mM}$ added-glucose treatment (ISO-0-20), we reduced the osmolarity of the GB (osmolarity 253.8 $\pm 0.6 \mathrm{mOsm}$, as measured in our laboratory by a vapor pressure osmometer (Wescor 5600, ELITechGroup, Princeton, NJ, USA)) by 22 mOsm using embryo-quality distilled water, and we used this as the base medium, to which $10 \%$ FBS and $20 \mathrm{mM}$ glucose were added.

Oocytes were obtained via TVA, matured in vitro, and subjected to ICSI as described earlier in the present paper using sperm from Stallion SP. Sperm-injected oocytes were allocated randomly to the $0-20$ and ISO-0-20 treatments. Both treatments utilized the same medium for the first 5 days of culture (0 GB with 10\% FBS). At day 5, cleaved embryos were transferred either to the $20 \mathrm{mM}$ glucose medium or to the ISO-20 mM medium. Blastocyst development was evaluated as in experiment 1.

\section{Statistical analysis}

Differences in rates of presumptive cleavage, rate of blastocyst development, and day of blastocyst development (day 7 vs days 8-11) among treatment groups were analyzed by Fisher's exact test (Epistat Statistical Package, V2.1, T. Gustafson, Round Rock, TX, USA). Differences in embryo morphological ICM scores among treatments and among embryo days, and differences in the day of development of embryos among treatments, were evaluated by the Kruskal-Wallace one-way ANOVA on ranks (SigmaPlot for Windows 13.0, Systat Software, San Jose, CA, USA). Differences in embryo diameter, nucleus number, and the proportion of cells stained with the different immunoreactive stains were evaluated by one-way ANOVA. Correlations among embryo diameter, total cell number, or ICM morphology score, and the number of TE, $\mathrm{PE}$, and EPI cells or the ratio of cell lineage types was evaluated by the Pearson product-moment correlation coefficient. These latter two analyses were conducted by the Data Analysis pack in Microsoft Excel 2010; significance for the Pearson statistic was assessed by the $t$ value. Consistency among ratings for ICM morphology was evaluated by the Cronbach Alpha statistic (Free Statistics Software, Office for Research Development and Education, version 1.1.23-r7, URL http://www.wessa.net/).

\section{Results}

\section{Experiment 1}

For this study, 86 slaughterhouse-derived ovaries were used, 598 follicles were scraped, and 288 oocytes were recovered. Among the recovered oocytes, 184 were classified as Ex, 72 as Cp, and 32 as degenerated. Only Ex oocytes were used for this experiment. After in vitro maturation, 11 oocytes were broken during cumulus removal and 104 of $173(60 \%)$ of the evaluated oocytes had formed a polar body. Six oocytes were broken during ICSI, and 98 injected oocytes were cultured. Three replicates, which represented a total of six to eight independent cultures (embryo culture droplets containing a maximum of five embryos per droplet), were performed per treatment. There were no significant differences in rates of presumptive cleavage (85-94\%), blastocyst formation (18-19\%), or day of blastocyst development among the DMEM/F-12, 0-20, and 20-20 treatments $(P>0.1$ for all parameters; Table 1$)$.

\section{Experiment 2}

Oocytes were recovered during 57 TVA sessions. A total of 719 follicles were aspirated, and 373 oocytes were recovered (52\% recovery rate). Of the 369 oocytes evaluated after maturation, 234 oocytes $(63 \%)$ had a polar body. Of these, 52 oocytes were used for a separate study, and 182 were used for the present study. One oocyte was broken during ICSI. Eight replicates, which represented a total of 12-14 independent cultures (embryo culture droplets), were performed per treatment. There were no significant differences in rates of presumptive cleavage or development to the blastocyst stage among the four glucose treatment groups (Table 2; $88-95 \%$ cleavage and $31-46 \%$ blastocyst respectively). However, the proportion of embryos that developed to blastocyst on day 7 was significantly higher in the 0-20 treatment than it was in any other treatment $(P<0.01$ to $P<0.05$ ).

Thirty-nine blastocysts were warmed after vitrification; three were lost during warming, and 36 were cultured for immunostaining. Of these, one embryo in the 0-10 treatment broke and formed a monolayer cell culture. Two 5-10 embryos and one 5-20 embryo failed to increase in diameter during culture and were therefore not submitted for immunostaining. Upon the immunostaining of 32 embryos, nine embryos were lost during processing. In the remaining 23 embryos $(n=6,6,6$, and 5 for the $0-10,0-20,5-10$, and 5-20 treatments respectively), all of the cells stained positively for

Table 1 Comparison of media for in vitro culture of slaughterhouse-derived oocytes fertilized by ICSI.

\begin{tabular}{|c|c|c|c|c|c|c|c|}
\hline In vitro culture medium & No. & $\begin{array}{c}\text { Presumptive } \\
\text { cleavage }^{\mathrm{a}} \text { no. }(\%)\end{array}$ & $\begin{array}{c}\text { Blastocyst no. } \\
\text { (\% of injected oocytes) }\end{array}$ & D7 & D8 & D9 & D10 \\
\hline DMEM/F-12 & 34 & $29(85)$ & $6(18)$ & 2 & 1 & 1 & 2 \\
\hline GB 0-20 & 33 & 31 (94) & $6(18)$ & 1 & 3 & 0 & 2 \\
\hline GB 20-20 & 31 & $28(90)$ & $6(19)$ & 1 & 2 & 1 & 2 \\
\hline
\end{tabular}

DMEM/F-12, culture in this medium throughout culture, with medium change at day 5; GB, Global human embryo culture medium; 0-20, culture with 0 added glucose for the first 5 days, then with $20 \mathrm{mM}$ added glucose; 20-20, culture with $20 \mathrm{mM}$ added glucose throughout culture, with medium change at day 5 . All media contained $10 \%$ fetal bovine serum.

${ }^{a}$ Cleavage was determined on day 5 , and thus this may include fragmented oocytes. 
Table 2 Blastocyst development after ICSI in equine embryos cultured under different glucose treatments.

\begin{tabular}{|c|c|c|c|c|c|c|c|c|}
\hline Treatment & No. & $\begin{array}{c}\text { Presumptive } \\
\text { cleavage }^{\mathrm{a}} \text { no. }(\%)\end{array}$ & $\begin{array}{c}\text { Morulae } \\
\text { no. }\end{array}$ & $\begin{array}{c}\text { Blastocysts no. (\% of } \\
\text { injected oocytes) }\end{array}$ & D7 & D8 & D9 & D10, 11 \\
\hline GB 0-10 & 42 & 37 (88) & 0 & $13(31)$ & $4^{b, c}$ & 5 & 1 & 3 \\
\hline GB 0-20 & 44 & 42 (95) & 1 & $18(41)$ & $14^{\mathrm{C}}$ & 1 & 0 & 3 \\
\hline GB 5-10 & 46 & $42(91)$ & 1 & $21(46)$ & $4^{b}$ & 10 & 4 & 3 \\
\hline GB 5-20 & 49 & $44(90)$ & 1 & 17 (35) & $6^{\mathrm{b}}$ & 2 & 7 & 2 \\
\hline
\end{tabular}

GB, Global human culture medium with $10 \%$ fetal bovine serum; 0-10, etc., culture with 0 added glucose for the first 5 days, then with 10 mM added glucose, etc.

Values with different superscripts differ significantly $(P<0.05)$.

${ }^{a}$ Cleavage was determined on day 5 , and thus this may include fragmented oocytes.

POU5F1, as has been previously reported for in vitroproduced embryos (Choi et al. 2009); cells that were positive for POU5F1 and negative for CDX2 and GATA6 were classified as EPI cells. There were no significant differences in diameter, total blastocyst cell number, or morphological score according to the day of blastocyst development (day 7,8 , or 9-11, $P<0.1$ ); nor was there a significant difference in the day of development of the embryos that were analyzed in each treatment $(8.2 \pm 0.5$, $8.3 \pm 0.7,8.2 \pm 0.3$, and $7.2 \pm 0.2$ for the $0-10,0-20$, 5-10, and 5-20 treatments respectively, mean \pm s.E.M., $P>0.1)$; thus, embryos of all development days were combined to analyze morphological parameters by treatment. Results of total cell count and counts of each cell lineage are presented in Fig. 1. There were no significant differences in total blastocyst cell number among treatments $(254.2 \pm 56.7-345.5 \pm 59.3$, mean \pm S.E.M.; $P>0.05)$. The number of EPI cells in blastocysts in the 5-20 treatment $(18.4 \pm 4.1)$ was significantly lower than that for blastocysts in the 0-20 treatment $(34.2 \pm 6.5, P<0.05)$, and it tended to be lower than that for blastocysts in the 0-10 treatment (34.5 $\pm 9.4, P<0.1)$. The mean percentage of EPI/total cells was not significantly different $(P>0.1)$ among treatment groups $(9.7 \pm 1.6,9.9 \pm 0.7,8.3 \pm 1.9$, and $7.4 \pm 1.4 \%$ for the $0-10,0-20,5-10$, and 5-20 treatments respectively) or among days of blastocyst development $(9.1 \pm 1.0,8.4 \pm 1.7,7.1 \pm 1.9$, and $10.8 \pm 0.1 \%$ for day $7,8,9$, and 10-11 blastocysts respectively; $n=10,7,3$, and 3 respectively). Similarly, the mean percentage of $(\mathrm{EPI}+\mathrm{PE}) /$ total cells did not differ significantly among groups $(35-43 \%, P>0.1)$ or the day of blastocyst development $(39-41 \%, P>0.1)$.

When embryos were grouped by final glucose treatment (10 vs $20 \mathrm{mM}$ ), there was no consistent trend between groups ( $P>0.2$ for all assessed parameters). When embryos were grouped by initial glucose treatment ( 0 vs $5 \mathrm{mM}$ ), embryos cultured initially in $5 \mathrm{mM}$ glucose tended to have a lower number of mitotic figures $(P<0.1)$, a lower proportion of embryos developing on days 7 and $8(P<0.1)$, a lower number of EPI cells $(P<0.1)$, and a lower ratio of EPI:TE $(P<0.1)$ and EPI:PE cells $(P<0.1)$ than did embryos initially cultured in $0 \mathrm{mM}$ glucose.
Correlations between embryo diameter and total cell number and the number of TE, PE, and EPI cells are given in Supplementary Table 1, see section on supplementary data given at the end of this article. Embryo diameter and total cell number were significantly and directly correlated with each other and with the numbers of TE, $\mathrm{PE}$, and EPI cells. There were no significant correlations between embryo diameter or total cell number and the proportions of TE, PE, and EPI cells.

Photomicrographs of embryos that demonstrated the three cell lineages on immunostaining and represented the different ICM morphology categories are presented in Fig. 2. Individual channels for each image are presented in Supplementary Figures 2 and 3, see section on supplementary data given at the end of this article. No organized separation of an ICM into an EPI (negative for GATA6 and CDX2) and hypoblast (GATA6-positive) was seen in any embryo; however, GATA6-positive cells could be visualized on the inner aspect of the trophoblast in the higher ICM category embryos (Fig. 2A and B). Mean morphological ICM scores on visual examination of stained images for each individual

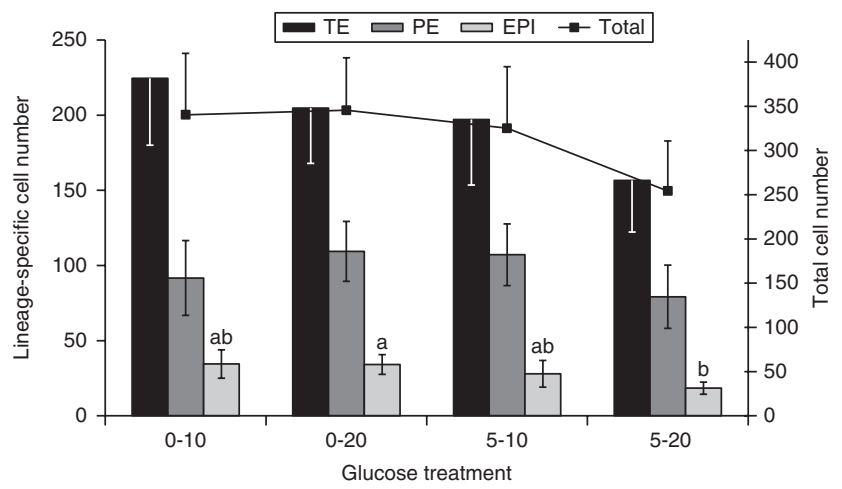

Figure 1 Cell lineage allocation (mean \pm s.E.m.) in equine blastocysts cultured in Global human culture medium (GB) with $10 \%$ fetal bovine serum containing different amounts of added glucose. 0-10, etc.: culture with 0 added glucose for the first 5 days, then with $10 \mathrm{mM}$ added glucose, etc. All nuclei were POU5F1-positive. TE, trophoblast (CDX2-positive); PE, primitive endoderm (GATA6-positive); EPI, presumptive epiblast cells (CDX2- and GATA6-negative). Values with different superscripts represent significant differences in the number of $\mathrm{EPI}$ cells between groups $(P<0.05)$. 

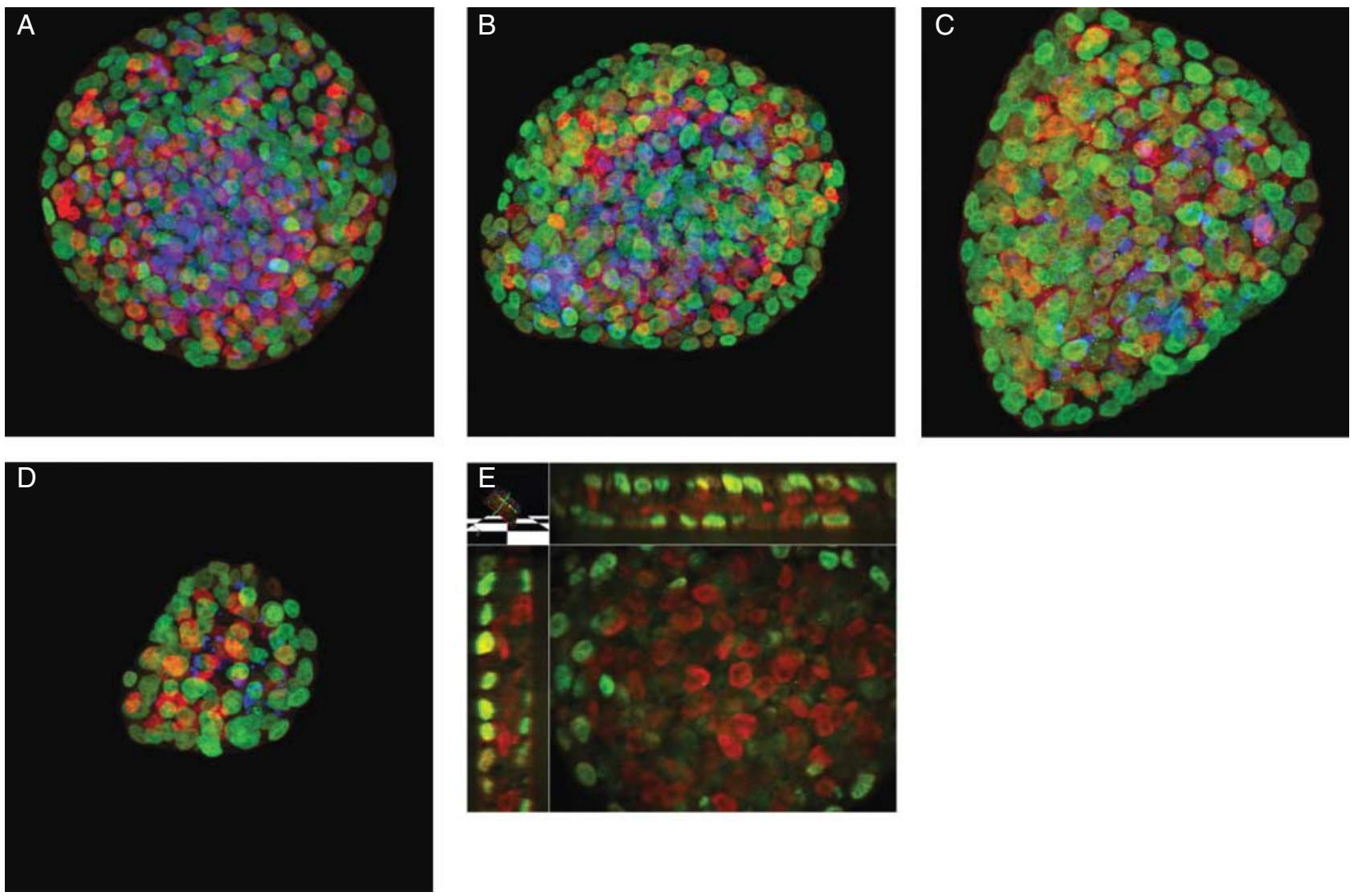

Figure 2 Photomicrographs of equine embryos after immunocytochemistry for cell lineage determination showing the four morphological ICM categories. All cells were positive for POU5F1. Green, CDX2 (trophoblast); red, GATA6 (endoderm); blue, CDX2- and GATA6-negative (EPI, presumptive epiblast). (A) Morphological ICM score 3 (0-20 treatment); note the presence of GATA6-positive cells lining the trophoblast. (B) Morphological ICM score 2 (0-10 treatment); note the separation of internal cells into more peripheral GATA6-positive cells and more central EPI cells. (C) Morphological ICM score 1 (5-10 treatment). (D) Morphological ICM score 0 (5-20 treatment). (E) 3D reconstruction of confocal images showing CDX2-positive cells (green) restricted to the outside of the embryo and GATA6 cells (red) restricted to the inside. Images (A, B, C and D) represent each category of ICM morphology; the distribution of the morphological scores within the treatments can be seen in Fig. 3.

embryo in the different treatments are presented in Fig. 3. The consistency among the four individual observer ratings for morphological ICM score was high (Cronbach's $\alpha=0.91$ ). Mean values were $1.8,1.8,1.4$, and 1.1 for embryos in the $0-10,0-20,5-10$, and 5-20 treatments respectively; there was no significant difference in the morphological score among the treatments $(P>0.1)$. The morphological ICM score was significantly correlated with embryo diameter $(P<0.05)$, total cell number $(P<0.01)$, the numbers of the individual cell lineage types $(P<0.05)$, and the ratios of EPI:TE and EPI:PE within the embryo $(P<0.05$, Supplementary Table 1$)$.

\section{Experiment 3}

For this experiment, 21 aspiration sessions were conducted, 244 follicles were aspirated, and 114 oocytes were collected. After $30 \mathrm{~h}$ in vitro maturation, 72 oocytes were mature (63\% maturation rate). Six replicates, which represented a total of ten independent cultures (embryo culture droplets), were performed per treatment. There were no significant differences in rates of cleavage (94 and $86 \%$ ), development to the blastocyst stage (33 and $31 \%$ respectively), or day of blastocyst development between embryos cultured in the $0-20$ or ISO-0-20 treatments respectively (Table 3).

\section{Discussion}

The present study demonstrates for the first time that efficient in vitro equine blastocyst production can be achieved in a medium containing minimal $(<1 \mathrm{mM})$ glucose during early cleavage-stage development. Embryos in the 5-20 treatment had a significant reduction in EPI cell number as compared to embryos in the 0-20 group and, although not statistically significant, had the lowest total cell number and lowest morphological score of all the treatments. These findings suggest that excess glucose during equine cleavage-stage development may exert effects similar to those reported in mouse and rat embryos (De Hertogh et al. 1991, Leunda-Casi et al. 2002). 


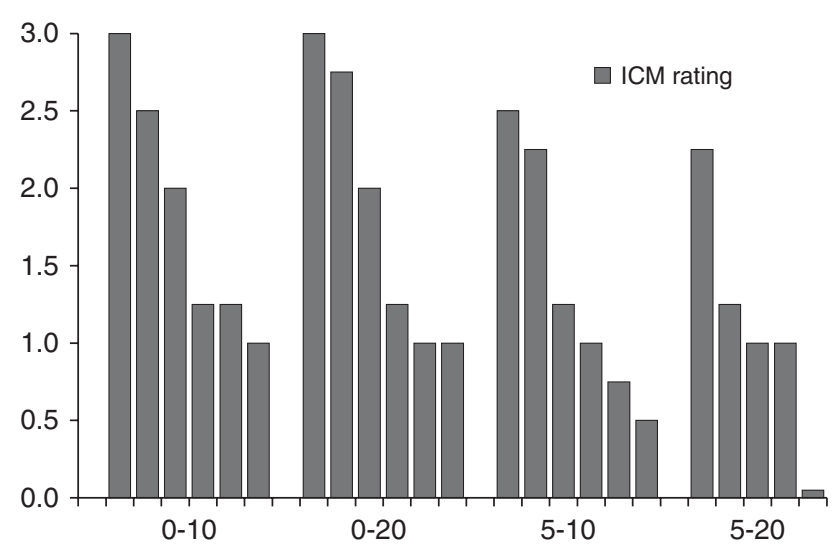

Figure 3 Morphological ICM scores for each individual embryo in the different glucose treatments. The degree of organization of inner cells was rated on a scale of 0 (minimal or no inner cells present) to 3 (multiple inner cells present and organized toward one pole as an apparent ICM); photomicrographs of embryos in each category are presented in Fig. 2. Each column represents the score for an individual embryo (mean of four independent observer ratings). 0-10, etc.: culture with 0 added glucose for the first 5 days, then with $10 \mathrm{mM}$ added glucose, etc.

Although there was a tendency for glucose in early culture to affect cell allocation, these findings reveal a notable tolerance of equine embryos for environmental glucose, as the rate of blastocyst development was similar in a wide range of glucose concentrations. Culture throughout development in DMEM/F-12-based media at $>16 \mathrm{mM}$ glucose has been associated with the highest equine blastocyst development rates previously reported (up to $43 \%$ per injected oocyte; Hinrichs et al. 2005, Ribeiro et al. 2008, Jacobson et al. 2010) and with normal embryo development after transfer to recipient mares (Choi et al. 2011). In reconciling this with the indications of a detrimental effect of $5 \mathrm{mM}$ glucose in a GB medium during early culture, it is possible that the very high glucose in DMEM/F-12 causes the inhibition of glucose transport, as has been described in mouse embryos in high-glucose environments (Moley et al. 1998), whereas the lower concentration (5 mM) allows glucose transport and subsequently impairs metabolism.

Alternatively, it is possible that there is an interaction of glucose and culture media (i.e., embryos may be more tolerant of glucose in DMEM/F-12 than of glucose in $\mathrm{GB})$, as has been suggested in the mouse; mouse embryos cultured in the medium KSOM were not adversely affected by presence of $5.6 \mathrm{mM}$ glucose during initial development (Summers et al. 1995). Although the composition of $\mathrm{GB}$ is not provided by its manufacturer, a recent publication analyzed the makeup of this and other commercial human embryo culture media (Morbeck et al. 2014). Comparing the values for the components presented in that publication for GB to the makeup of DMEM/F-12 as given by the manufacturer (D8900; Sigma-Aldrich) shows that components with a greater than fourfold difference between media are (values given respectively for GB and DMEM/F-12): glucose (0.2 vs $17.5 \mathrm{mM})$; lactate ( 4.8 vs $0 \mathrm{mM})$; glutamine ( 0 vs $2.5 \mathrm{mM}$ ); serine (58 vs $250 \mu \mathrm{M}$ ); chromium, aluminum, manganese and cobalt (all present in micromolar quantities in $\mathrm{GB}$ but not in $\mathrm{DMEM} / \mathrm{F}-12$ ); and copper, zinc, and iron (all present in micromolar quantities in DMEM/F-12 but not in GB).

The present findings also point out a tolerance of equine embryos for a wide range of osmolarities; GB (254 mOsm by our measurement) with $10 \%$ FBS ( 310 (280-340) mOsm; \#10082-147; Invitrogen) has an initial osmolarity of $\sim 260$ mOsm; this increases if glucose is added to reach $\sim 290$ mOsm in the $20 \mathrm{mM}$ glucose group. The osmolarity of DMEM/F-12 (284-310 mOsm; Sigma-Aldrich) with $10 \%$ FBS is $\sim 300 \mathrm{mOsm}$. The combined results of our experiments, in which an equivalent percentage of equine embryos developed in high (DMEM/F-12 and 20-20 medium) changing (e.g., 0-20) and low (ISO-0-20) osmolarity media, suggest that equine embryos do not have a distinct preference for osmolarity within the values tested. Embryos produced using these culture media appear to be viable, as reflected in the rates of normal pregnancy (to at least the heartbeat stage) after their transfer to recipient mares: DMEM/F-12 (12/17, 71\%; Choi et al. 2011); 0-20 GB (clinical embryo production) (66/101, 66\%; Hinrichs et al. 2014); 5-20 GB (3/4, 75\%; K Hinrichs, YH Choi and FL Riera, unpublished observations). It is clear that much further research is needed on the requirements of the equine embryo for optimal development in vitro, and it is hoped that the present findings will stimulate work in this area. Unfortunately, the closure of all equine slaughterhouses in the United States in 2007, and the resulting scarcity of oocytes with which to work, has greatly hindered our ability to explore these questions extensively.

Table 3 Influence of maintenance of iso-osmolar conditions throughout culture on blastocyst development after ICSI in GB medium with 0 then $20 \mathrm{mM}$ added glucose.

\begin{tabular}{lccccccc}
\hline Treatment & No. & $\begin{array}{c}\text { Presumptive }_{\text {cleavage }^{\mathrm{a}} \text { no. }(\%)} \\
\text { Morulae no. }\end{array}$ & $\begin{array}{c}\text { Blastocysts no. } \\
\text { (\% of injected oocytes) }\end{array}$ & D7 & D8 & D9 & D10, 11 \\
\hline GB 0-20 (control) & 36 & $34(94)$ & 0 & $12(33)$ & 5 & 2 & 4 \\
GB ISO-0-20 & 36 & $31(86)$ & 0 & $11(31)$ & 8 & 3 & 0 \\
\hline
\end{tabular}

GB 0-20 (control), incubation in GB $+10 \%$ FBS for 5 days, followed by incubation in GB $+10 \%$ FBS +20 mM added glucose; GB ISO-0-20, as above but osmolarity adjusted with distilled water in the $20 \mathrm{mM}$ glucose medium to render it iso-osmolar to GB $+10 \%$ FBS.

${ }^{a}$ Cleavage was determined on day 5 , and thus this may include fragmented oocytes. 
The rate of blastocyst development in experiment 1 was relatively low for both DMEM/F-12 and GB 0-20; this could be the result of the oocyte source (slaughterhouse in experiment 1 vs TVA for experiments 2 and 3), different in vitro systems (a newly set up laboratory in Argentina vs an established laboratory in Texas), the use of a different stallion as the semen source for ICSI, or, for $\mathrm{GB}$, the use of different $\mathrm{CO}_{2}$ concentrations for culture ( $5 \%$ in experiment 1 , which was used because this was the atmosphere at which we have previously used DMEM/F-12 successfully, vs $6 \%$ in experiment 2, which was used with GB after intervening trials with this medium). The blastocyst rates per injected oocyte achieved with GB in experiment 2 (up to $46 \%$ ) are equivalent to the highest we have achieved with DMEM/F-12 (43\%; Ribeiro et al. 2008). Although the highest numeric blastocyst development in the present study was achieved in the 5-10 treatment, the suggestion that blastocyst quality was lower (a tendency for a lower rate of mitosis, a lower number of EPI cells (discussed further later in this section), and later development for blastocysts) when $5 \mathrm{mM}$ glucose was added to the first stage of culture might lead one to select the $0-10$ or $0-20$ treatments as the treatments of choice for blastocyst production in a clinical program. Of these, the $0-20$ treatment may be preferred, because it produced $41 \%$ blastocysts vs $31 \%$ for the $0-10$ treatment, and it tends to support a higher proportion of EPI+PE cells to trophoblast cells than does the 0-10 treatment (Fig. 1). It also supported a greater rate of development on day 7 . Regarding this last parameter, although the rate of development on day 7 was significantly higher for the 0-20 treatment than it was for all of the other glucose treatments run concurrently in experiment $2(14 / 18$ embryos developed to blastocyst on day 7), the 0-20 treatment did not show a similar pattern in experiments 1 or 3. This discrepancy may be a result of oocyte factors (e.g., experiment 2 was conducted in the early to midbreeding season (March-June), and experiment 3 was conducted in the late season (August-September) the following year) or of laboratory variation, but it indicates that variability exists in the rate of development to blastocyst within this treatment.

The present findings on immunocytochemistry suggest that staining for trophoblast and PE cell lineages may provide a needed method to help define the parameters that reflect blastocyst quality in in vitro-produced equine embryos. Evaluating the quality of equine in vitroproduced embryos has been complicated by the inability to use a standard differential staining technique to evaluate ICM cells (Hinrichs et al. 2007). This appears to be related to the characteristics of equine blastocyst formation. In early equine blastocysts, a central network of cells is found within a defined trophoblastic rim (Fig. 2). This has been demonstrated previously not only in in vitro-produced equine embryos (Tremoleda et al. 2003, Hinrichs et al. 2007) but also in early equine blastocysts that were recovered from mares on day 6 after ovulation (Bruyas et al. 1993, 1995). We found that the central cell network of the horse embryo consists of a mixture of EPI and PE cells, which is similar to findings in very early blastocysts in mice and cattle (Chazaud et al. 2006, Kuijk et al. 2012, Schrode et al. 2014). However, in mice and cattle, as the blastocyst develops, the EPI and PE cells aggregate to form a discrete ICM, and then segregate into EPI and hypoblast (Kuijk et al. 2012, Schrode et al. 2014). We did not find evidence of these stages; rather, as equine blastocysts increased in morphological ICM score, PE cells were found to be distributed on the inner surface of the trophoblast, whereas EPI cells aggregated loosely toward one pole (Fig. 2A and B). These findings support the thin-section and electron-micrographic evidence presented by Enders et al. (1993) in in vivo-recovered embryos. They reported that the primitive endoderm cells of the equine embryo appeared to migrate directly from the central cell network to the inner aspect of the trophoblast during blastocyst formation. This is in contrast to the development of the primitive endoderm as it is understood in other species: for example, in mice, the cells in the center of the early blastocyst contain a mixture of EPI and PE cells, but they first form a discrete ICM, and then segregate to EPI and hypoblast, after which the PE cells migrate out from the hypoblast to line the blastocoele (Chazaud et al. 2006, Schrode et al. 2014). Temporal evaluation of in vivo- and in vitro-produced equine embryos is needed to definitively establish the sequence of allocation of GATA6-positive cells and EPI cells in this species.

To the best of our knowledge, this is the first description of cell lineage allocation in in vitroproduced, fertilized equine embryos. Tremoleda et al. (2003) evaluated cytoskeletal morphology and apoptosis in ICSI-produced embryos and reported that the ICM was poorly organized. Desmarais et al. (2011) evaluated POU5F1 and GATA6 in in vivo-recovered, parthenogenetic, and nuclear transfer-derived equine embryos; they found a small number of POU5F1-positive but GATA6negative cells in day 7 in vivo embryos and concluded that the ICM had differentiated into EPI and hypoblast at that time. In contrast to the present findings with ICSIproduced embryos, Desmarais et al. (2011) reported that in parthenogenetic and nuclear transfer-derived equine embryos, staining for GATA6 was found in both inner cells and trophoblast cells. This may reflect a failure of effective differentiation of the trophoblast in these nonfertilized embryos or differences in their preparation for antibody staining. The investigators did not probe embryos with a trophoblast-specific antibody.

Although staining for trophoblast and PE cell lineages provides information on blastocyst makeup, currently no information is available on the normal allocation of cell lineage in equine blastocysts, so meaningful interpretation of differences in EPI or PE cell numbers or ratios 
among treatments is not yet possible. An increase in ICM proportion is not in itself necessarily beneficial: in cattle, embryos with lower viability (produced by nuclear transfer) actually had higher ICM/total cell ratios than did IVF or in vivo-recovered embryos (Koo et al. 2002). Even defining the term 'ICM/total cell ratio' appears to be problematic in equine embryos, because the ICM in other species consists of both EPI and PE cells (EPI and hypoblast), whereas we did not recognize this stage of ICM formation in our equine embryos. We found that EPI cells averaged between 7 and $10 \%$ of the total cells; this is low compared to the ICM/total cell number reported in other species (20-30\%, murine, bovine, porcine, and rabbit; Giles \& Foote 1995, de la Fuente \& King 1997). However, this excludes PE cells; the inclusion of PE cells in the ICM cell count would include PE cells already positioned at the periphery of the blastocoele.

The results of these studies add to our understanding of equine embryo development and provide information on embryo culture conditions that support the production of equine blastocysts in vitro. Further work is needed to better define the metabolic requirements of equine embryos and to establish the parameters of cell lineage allocation that indicate normal viability in order to optimize the results obtained with this valuable research and clinical procedure.

\section{Supplementary data}

This is linked to the online version of the paper at http://dx.doi. org/10.1530/REP-14-0662.

\section{Declaration of interest}

The authors declare that there is no conflict of interest that could be perceived as prejudicing the impartiality of the research reported.

\section{Funding}

The present study was supported by the Link Equine Research Endowment Fund, Texas A\&M University, and by Ms Kit Knotts.

\section{Acknowledgements}

The authors thank Ms J Norris, Ms S Spacek, Dr K Iqbal, and Mrs Y Bogliotti for their excellent technical assistance. We thank Dr Don Rieger, LifeGlobal Group, LLC, for their initial donation of GB media.

\section{References}

Abràmoff MD, Magelhaes PJ \& Ram SJ 2004 Image processing with ImageJ. Biophotonics International 11 36-42.

Bruyas JF, Bezard J, Lagneaux D \& Palmer E 1993 Quantitative analysis of morphological modifications of day 6.5 horse embryos after cryopreservation: differential effects on inner cell mass and trophoblast cells. Journal of Reproduction and Fertility 99 15-23. (doi:10.1530/jrf.0. 0990015)

Bruyas JF, Battut I, Pol JM, Botrel C, Fieni F \& Tainturier D 1995 Quantitative analysis of morphological modifications of day 6.5 horse embryos after treatment with four cryoprotectants: differential effects on inner cell mass and trophoblast cells. Biology of Reproduction Monograph Series 1 329-339.

Chatot CL, Ziomek CA, Bavister BD, Lewis JL \& Torres I 1989 An improved culture medium supports development of random-bred 1-cell mouse embryos in vitro. Journal of Reproduction and Fertility 86 679-688. (doi:10.1530/jrf.0.0860679)

Chazaud C, Yamanaka Y, Pawson T \& Rossant J 2006 Early lineage segregation between epiblast and primitive endoderm in mouse blastocysts through the Grb2-MAPK pathway. Developmental Cell 10 615-624. (doi:10.1016/j.devcel.2006.02.020)

Choi YH, Love CC, Love LB, Varner DD, Brinsko S \& Hinrichs K 2002 Developmental competence in vivo and in vitro of in vitro-matured equine oocytes fertilized by intracytoplasmic sperm injection with fresh or frozen-thawed spermatozoa. Reproduction 123 455-465. (doi:10. 1530/rep.0.1230455)

Choi YH, Love CC, Varner DD, Love LB \& Hinrichs K 2003 a Effects of gas conditions, time of medium change, and ratio of medium to embryo on in vitro development of horse oocytes fertilized by intracytoplasmic sperm injection. Theriogenology 59 1219-1229. (doi:10.1016/S0093691X(02)01164-0)

Choi YH, Chung YG, Walker SC, Westhusin ME \& Hinrichs K 2003 b In vitro development of equine nuclear transfer embryos: effects of oocyte maturation media and amino acid composition during embryo culture. Zygote 11 77-86. (doi:10.1017/S0967199403001102)

Choi YH, Roasa LM, Love CC, Varner DD, Brinsko SP \& Hinrichs K 2004a Blastocyst formation rates in vivo and in vitro of in vitro-matured equine oocytes fertilized by intracytoplasmic sperm injection. Biology of Reproduction 70 1231-1238. (doi:10.1095/biolreprod.103.023903)

Choi YH, Love LB, Varner DD \& Hinrichs K 2004b Factors affecting developmental competence of equine oocytes after intracytoplasmic sperm injection. Reproduction 127 187-194. (doi:10.1530/rep.1.00087)

Choi YH, Love LB, Varner DD \& Hinrichs K 2006 Holding immature equine oocytes in the absence of meiotic inhibitors: effect on germinal vesicle chromatin and blastocyst development after intracytoplasmic sperm injection. Theriogenology 66 955-963. (doi:10.1016/j.theriogenology. 2006.01.064)

Choi YH, Love LB, Varner DD \& Hinrichs K 2007 Effect of holding technique and culture drop size in individual or group culture on blastocyst development after ICSI of equine oocytes with low meiotic competence. Animal Reproduction Science 102 38-47. (doi:10.1016/ j.anireprosci.2006.09.028)

Choi YH, Harding HD, Hartman DL, Obermiller AD, Kurosaka S, McLaughlin KJ \& Hinrichs K 2009 The uterine environment modulates trophectodermal POU5F1 levels in equine blastocysts. Reproduction 138 589-599. (doi:10.1530/REP-08-0394)

Choi YH, Varner DD, Love CC, Hartman DL \& Hinrichs K 2011 Production of live foals via intracytoplasmic injection of lyophilized sperm and sperm extract in the horse. Reproduction 142 529-538. (doi:10.1530/ REP-11-0145)

Choi YH, Velez IC, Macías-García B \& Hinrichs K 2013 Application of an open device to vitrify equine in vitro-produced embryos. Reproduction, Fertility, and Development 25178 (abstract). (doi:10.1071/RDv25 n1Ab61)

Conaghan J, Handyside AH, Winston RML \& Leese HJ 1993 Effects of pyruvate and glucose on the development of human preimplantation embryos in vitro. Journal of Reproduction and Fertility 99 87-95. (doi:10.1530/jrf.0.0990087)

De Hertogh R, Vanderheyden I, Pampfer S, Robin D, Dufrasne E \& Delcourt J 1991 Stimulatory and inhibitory effects of glucose and insulin on rat blastocyst development in vitro. Diabetes 40 641-647. (doi:10.2337/diab.40.5.641)

Dell'Aquila ME, Cho YS, Minoia P, Traina V, Lacalandra GM \& Maritato F 1997 Effects of follicular fluid supplementation of in-vitro maturation medium on the fertilization and development of equine oocytes after in-vitro fertilization or intracytoplasmic sperm injection. Human Reproduction 12 2766-2772. (doi:10.1093/humrep/12.12.2766) 
Desmarais JA, Demers SP, Suzuki JJ, Laflamme S, Vincent P, Laverty S \& Smith LC 2011 Trophoblast stem cell marker gene expression in inner cell mass-derived cells from parthenogenetic equine embryos. Reproduction 141 321-332. (doi:10.1530/REP-09-0536)

Enders AC, Schlafke S, Lantz KC \& Liu IKM 1993 Endoderm cells of the equine yolk sac from day 7 until formation of the definitive yolk sac placenta. Equine Veterinary Journal Supplement 15 3-9. (doi:10.1111/ j.2042-3306.1993.tb04814.x)

Freeman DA, Weber JA, Geary RT \& Woods GL 1991 Time of embryo transport through the mare oviduct. Theriogenology 36 823-830. (doi:10.1016/0093-691X(91)90348-H)

de la Fuente J \& King WA 1997 Use of a chemically defined system for the direct comparison of inner cell mass and trophectoderm distribution in murine, porcine and bovine embryos. Zygote 5 309-320. (doi:10. 1017/S0967199400003890)

Furnus CC, de Matos DG, Martínez AG \& Matkovic M 1997 Effect of glucose on embryo quality and post-thaw viability of in-vitro-produced bovine embryos. Theriogenology 47 481-490. (doi:10.1016/S0093-691X (97)00006-X)

Gardner DK 1998 Changes in requirements and utilization of nutrients during mammalian preimplantation embryo development and their significance in embryo culture. Theriogenology 49 83-102. (doi:10. 1016/S0093-691X(97)00404-4)

Gardner DK, Schoolcraft WB, Wagley L, Schlenker T, Stevens J \& Hesla J 1998 A prospective randomized trial of blastocyst culture and transfer in in-vitro fertilization. Human Reproduction 13 3434-3440. (doi:10.1093/ humrep/13.12.3434)

Giles JR \& Foote RH 1995 Rabbit blastocyst: allocation of cells to the inner cell mass and trophectoderm. Molecular Reproduction and Development 41 204-211. (doi:10.1002/mrd.1080410211)

Herrera C, Revora M, Vivani L, Miragaya MH, Lossino L, Quintans C, Pasqualini RS 2008 Effect of high glucose concentrations during in vitro culture of equine embryos (abstract). Proceedings, 7th International Symposium on Equine Embryo Transfer, pp 52-53. R\&W Communication, Suffolk, UK.

Hinrichs K 2010 The equine oocyte: factors affecting meiotic and developmental competence. Molecular Reproduction and Development 77 651-661. (doi:10.1002/mrd.21186)

Hinrichs K, Schmidt AL, Friedman PP, Selgrath JP \& Martin MG 1993 In vitro maturation of horse oocytes: characterization of chromatin configuration using fluorescence microscopy. Biology of Reproduction 48 363-370. (doi:10.1095/biolreprod48.2.363)

Hinrichs K, Choi YH, Love LB, Varner DD, Love CC \& Walckenaer BE 2005 Chromatin configuration within the germinal vesicle of horse oocytes: changes post mortem and relationship to meiotic and developmental competence. Biology of Reproduction 72 1142-1150. (doi:10.1095/ biolreprod.104.036012)

Hinrichs K, Choi YH, Walckenaer BE, Varner DD \& Hartman DL 2007 In vitro-produced equine embryos: production of foals after transfer, assessment by differential staining and effect of medium calcium concentrations during culture. Theriogenology 68 521-529. (doi:10. 1016/j.theriogenology.2007.04.046)

Hinrichs K, Choi YH, Love CC \& Spacek S 2014 Use of in vitro maturation of oocytes, intracytoplasmic sperm injection and in vitro culture to the blastocyst stage in a commercial equine assisted reproduction program. Journal of Equine Veterinary Science 34176 (abstract). (doi:10.1016/ j.jevs.2013.10.129)

Jacobson CC, Choi YH, Hayden SS \& Hinrichs K 2010 Recovery of mare oocytes on a fixed biweekly schedule, and resulting blastocyst formation after intracytoplasmic sperm injection. Theriogenology 73 1116-1126. (doi:10.1016/j.theriogenology.2010.01.013)

Koo DB, Kang YK, Choi YH, Park JS, Kim HN, Oh KB, Son DS, Park H, Lee KK \& Han YM 2002 Aberrant allocations of inner cell mass and trophectoderm cells in bovine nuclear transfer blastocysts. Biology of Reproduction 67 487-492. (doi:10.1095/biolreprod67.2.487)

Kuijk EW, van Tol LTA, Van de Velde H, Wubbolts R, Welling M, Geijsen N \& Roelen BAJ 2012 The roles of FGF and MAP kinase signaling in the segregation of the epiblast and hypoblast cell lineages in bovine and human embryos. Development 139 871-882. (doi:10.1242/dev.071688)

Lane M \& Gardner DK 2007 Embryo culture medium: which is the best? Best Practice \& Research. Clinical Obstetrics \& Gynaecology 21 83-100. (doi:10.1016/j.bpobgyn.2006.09.009)
Lane M, O'Donovan MK, Squires EL, Seidel GE Jr \& Gardner DK 2001 Assessment of metabolism of equine morulae and blastocysts. Molecular Reproduction and Development 59 33-37. (doi:10.1002/mrd.1004)

Lane M, Gardner DK, Hasler MJ \& Hasler JF 2003 Use of G1.2/G2.2 media for commercial bovine embryo culture: equivalent development and pregnancy rates compared to co-culture. Theriogenology 60 407-419. (doi:10.1016/S0093-691X(03)00030-X)

Leunda-Casi A, Genicot G, Donnay I, Pampfer S \& De Hertogh R 2002 Increased cell death in mouse blastocysts exposed to high D-glucose in vitro: implications of an oxidative stress and alterrations in glucose metabolism. Diabetologia 45 571-579. (doi:10.1007/s00125-001-0752-y)

Li X, Morris LHA \& Allen WR 2001 Influence of co-culture during maturation on the developmental potential of equine oocytes fertilized by intracytoplasmic sperm injection (ICSI). Reproduction 121 925-932. (doi:10.1530/rep.0.1210925)

Ludwig TE, Lane M \& Bavister BD 2001 Differential effect of hexoses on hamster embryo development in culture. Biology of Reproduction 64 1366-1374. (doi:10.1095/biolreprod64.5.1366)

Moley KH, Chi MMY \& Mueckler MM 1998 Maternal hyperglycemia alters glucose transport and utilization in mouse preimplantation embryos. American Journal of Physiology: Endocrinology and Metabolism 275 E38-E47.

Morbeck DE, Krisher RL, Herrick JR, Baumann NA, Matern D \& Moyer T 2014 Composition of commercial media used for human embryo culture. Fertility and Sterility 102 759-766. (doi:10.1016/j.fertnstert. 2014.05.043)

Ribeiro BI, Love LB, Choi YH \& Hinrichs K 2008 Transport of equine ovaries for assisted reproduction. Animal Reproduction Science 108 171-179. (doi:10.1016/j.anireprosci.2007.08.001)

Rieger D, Lagneau-Petit D \& Palmer E 1987 Preliminary investigations of the metabolic activity of early horse embryos. Journal of Reproduction and Fertility. Supplement 35 699-700.

Rieger D, Loskutoff NM \& Betteridge KJ 1992 Developmentally related changes in the metabolism of glucose and glutamine by cattle embryos produced and co-cultured in vitro. Journal of Reproduction and Fertility 95 585-595. (doi:10.1530/jrf.0.0950585)

Schini SA \& Bavister BD 1988 Two-cell block to development of cultured hamster embryos is caused by phosphate and glucose. Biology of Reproduction 39 1183-1192. (doi:10.1095/biolreprod39.5.1183)

Schrode N, Saiz N, Di Talia S \& Hadjantonakis AK 2014 GATA6 levels modulate primitive endoderm cell fate choice and timing in the mouse blastocyst. Developmental Cell 29 454-467. (doi:10.1016/j.devcel. 2014.04.011)

Seshagiri PB \& Bavister BD 1991 Glucose and phosphate inhibit respiration and oxidative metabolism in cultured hamster eight-cell embryos: evidence for the "crabtree effect". Molecular Reproduction and Development 30 105-111. (doi:10.1002/mrd.1080300206)

Summers MC, Bhatnagar PR, Lawitts JA \& Biggers JD 1995 Fertilization in vitro of mouse ova from inbred and outbred strains: complete preimplantation embryo development in glucose-supplemented KSOM. Biology of Reproduction 53 431-437. (doi:10.1095/biolreprod53.2.431)

Takahashi Y \& First NL 1992 In vitro development of bovine one-cell embryos: influence of glucose, lactate, pyruvate, amino acids and vitamins. Theriogenology 37 963-978. (doi:10.1016/0093-691X(92) 90096-A)

Thompson JG, Simpson AC, Pugh PA \& Tervit HR 1992 Requirement for glucose during in vitro culture of sheep preimplantation embryos. Molecular Reproduction and Development 31 253-257. (doi:10.1002/ mrd.1080310405)

Tremoleda JL, Stout TAE, Lagutina I, Lazzari G, Bevers MM, Colenbrander B \& Galli C 2003 Effects of in vitro production on horse embryo morphology, cytoskeletal characteristics, and blastocyst capsule formation. Biology of Reproduction 69 1895-1906. (doi:10.1095/ biolreprod.103.018515)

Received 27 June 2014

First decision 18 July 2014

Revised manuscript received 2 March 2015

Accepted 7 April 2015 